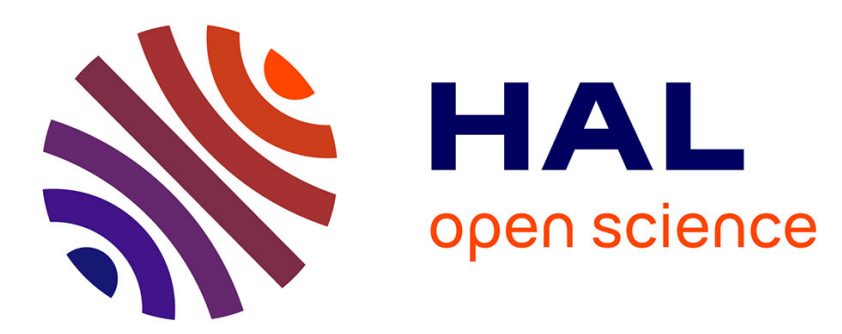

\title{
Qualification of multi-skilled human resources under knowledge depreciation and company skill level targets
}

Rainer Kolisch, Christian Heimerl

\section{To cite this version:}

Rainer Kolisch, Christian Heimerl. Qualification of multi-skilled human resources under knowledge depreciation and company skill level targets. International Journal of Production Research, 2010, 48 (13), pp.3759-3781. 10.1080/00207540902852785 . hal-00593337

\section{HAL Id: hal-00593337 https://hal.science/hal-00593337}

Submitted on 14 May 2011

HAL is a multi-disciplinary open access archive for the deposit and dissemination of scientific research documents, whether they are published or not. The documents may come from teaching and research institutions in France or abroad, or from public or private research centers.
L'archive ouverte pluridisciplinaire HAL, est destinée au dépôt et à la diffusion de documents scientifiques de niveau recherche, publiés ou non, émanant des établissements d'enseignement et de recherche français ou étrangers, des laboratoires publics ou privés. 


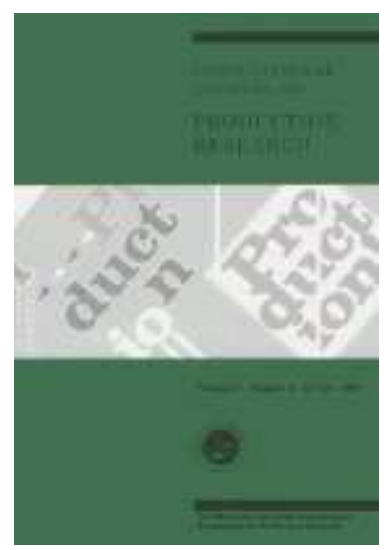

\section{Qualification of multi-skilled human resources under knowledge depreciation and company skill level targets}

\begin{tabular}{|r|l|}
\hline Journal: & International Journal of Production Research \\
\hline Manuscript ID: & TPRS-2008-IJPR-0589.R1 \\
\hline Manuscript Type: & Original Manuscript \\
\hline Date Submitted by the \\
Author: & 22-Dec-2008 \\
\hline Keyplete List of Authors: & $\begin{array}{l}\text { Kolisch, Rainer; Technische Universität München, TUM Business } \\
\text { School } \\
\text { Heimerl, Christian; Technische Universität München, TUM Business } \\
\text { School }\end{array}$ \\
\hline Keywords (user): & $\begin{array}{l}\text { HUMAN RESOURCE MANAGEMENT, RESOURCE PLANNING, } \\
\text { LEARNING CURVES, KNOWLEDGE MANAGEMENT }\end{array}$ \\
\hline \multicolumn{2}{|l}{} \\
\hline \multicolumn{2}{|l}{}
\end{tabular}

\section{$\diamond$ ScholarONE" \\ Manuscript Central}




\title{
Work assignment to and qualification of multi-skilled human resources under knowledge depreciation and company skill level targets
}

\author{
Christian Heimerl and Rainer Kolisch \\ TUM Business School \\ Technische Universität München, Germany \\ e-mail: christian.heimerl@wi.tum.de,rainer.kolisch@wi.tum.de
}

July 23, 2008

1st revision: December 22, 2008 


\title{
Work assignment to and qualification of multi-skilled human resources under knowledge depreciation and company skill level targets
}

\begin{abstract}
Assigning work to human resources is an important and common task for companies with high labour intensities. It is particularly complex if human resources have multiple skills and if their efficiencies change due to learning and depreciation of knowledge depending on the tasks they are assigned to. In this context, up to now, only little work has considered strategic targets for company skill levels. Hence, we present an optimization model to address the problem of assigning project work to multi-skilled internal and external human resources while considering learning, depreciation of knowledge and company skill level targets. This constrained non-linear continuous model is solved using COIN-OR's Ipopt. We assess the computation time and the impacts of problem parameters like the shape of the learning curve, company skill level targets, depreciation of knowledge and cost parameters. Amongst other findings, our results show that faster learning of human resources leads to more specialized individuals while at the same time the whole company's knowledge is broadened.
\end{abstract}

Keywords: Project staffing; Resource assignment; Multi-skilled resources; Learning; Forgetting 


\section{Introduction}

Assigning project work to human resources (henceforth called resources) taking into account resource-specific skills and efficiencies is a general planning task which has to be performed in any organization. It is of particular importance for service firms where the labour intensity is high (cf. e.g. Brusco [9]). The multi-skill assignment problem is an important variant of this planning problem. It requires work packages with a certain demand for one out of several skills to be assigned to resources with multiple skills (cf. Heimerl and Kolisch [21]). Because of its importance considerable effort has been devoted to address this problem class, and various models and solution methods have been proposed in literature (e.g. cf. Alba and Chicano [2], Ballou and Tayi [4], Bassett [5], Bellenguez and Néron [6], Gutjahr et al. [19]).

Concerning assignment decisions previous research followed two different approaches: Several authors (e.g. [1, 6, 7, 9-11, 13, 15, 26, 27, 33-35, 39]) assume a discrete 0-1 assignment of resources to tasks. This approach is appropriate if e.g. transfer times between tasks (e.g. due to travelling) are relatively high and cannot be neglected (cf. Krüger and Scholl [24]), the lengths of the periods are relatively short, or the transfer between tasks must occur concurrently (e.g. due to a minimum number of resources per task constraint). Other publications (cf. e.g. [2, 4, 18-21, 23, 42]) allow (continuous or discrete) fractional assignments of resources to tasks. With this assumption it is possible to model multi-tasking of resources which is a realistic assumption for period lengths of weeks or months. While from a mathematical point of view, the continuous problem is easier solve, the interpretation of the fractional assignment results within a period remains as a subsequent problem to solve.

Usually there are company-and/or resource-specific goals that assignment problems want to achieve: Company-specific goals can be the maximization of the company's revenue [1, 25], the maximization of the company's utility [11,31], the maximization of the company's performance or productivity $[13,25,27]$, the minimization of costs for (external) resources $[5,7,10,17,39,40]$ and/or overtime [7, 17], the minimization of project duration $[6,34]$ or the optimization of other performance indicators [22]. Typical resource-specific goals are the maximization of the resources' satisfaction [1, 42], the maximization of preferences or priorities for a task [15], the maximization of appropriateness for a task [4], the minimization of the resources' boredom [17], the maximization of skill improvement [19, 31], equalizing workload among resources $[10,17]$ or compliance with soft-constraints like a limit on the maximum number of similar tasks per resource [16].

Only few of these aforementioned models consider learning effects of resources (cf. e.g. Gutjahr et al. [19], Wu and Sun [39]). Instead, most models assume static and often homogeneous efficiencies of resources. However, efficiencies of resources are usually dynamic due to the acquisition of knowledge, such that more experienced resources have learned and therefore have higher efficiencies. Learning effects can be observed for repetitive tasks in manual, cognitive and knowledge-based work (cf. e.g. 
Arzi and Shtub [3], Boh et al. [8], Nembhard and Uzumeri [29]). Boh et al. [8] show that learning effects are present in special project environments with knowledgebase work, too. Wright [38] introduced learning curves as a common way to describe learning processes and an extensive amount of literature deals with different types of learning curves (cf. e.g. Nembhard and Uzumeri [28], Yelle [41] for an overview). On the other hand there is depreciation of knowledge. This effect is considered by even fewer assignment models (cf. e.g. Gutjahr et al. [19], Nembhard [26], Süer and Tummaluri [32]). Depreciation of knowledge can be caused by internal and/or external effects. Internal effects can depict e.g. forgetting, external effects can represent e.g. technological progress, which renders some older experience useless in the new environment or requires learning of new concepts in order to maintain efficiency (cf. Chen and Edgington [12]).

In this paper we address the problem of assigning project work to resources. We assume that project schedules are given and that project work can be aggregated across individual projects such that we obtain a resource demand for each skill and period of e.g. one month length. The aggregation enables the use of continuous assignment decisions. Learning and depreciation of knowledge of resources is taken into account and in this context we try to achieve two company-specific goals: The operative goal is to minimize costs for performing a given amount of project work during the planning horizon. On a strategic level, however, we need to decide who is applying and improving which skills in order to obtain given company skill level targets measured in production rates. The latter goal is expressed as a constraint. Of course, assignment problems can be applied to arbitrary-sized organizational units, e.g. companies, departments, or groups. W.l.o.g. we will refer to the organizational unit of a company for the remainder of this paper.

To the best of our knowledge, the aforementioned problem has only been scarcely discussed in the literature. Nembhard [26] solves the problem of assigning resources to skills with assignment policies but does not consider depreciation of knowledge or strategic goals. Wu and Sun [39] apply a meta-heuristic to the scheduling and staffing problem of projects w.r.t. learning but they neglect depreciation of knowledge and strategic goals, as well.

Our approach has many similarities with Gutjahr et al. [19]. Both models use multi-skilled resources and apply the concept of learning and forgetting. However, Gutjahr et al. [19] employ an objective function maximizing the weighted sum of strategic goals (learning perspective) and portfolio value while we minimize costs in the objective function and use constraints in order to accomplish the strategic goals. We neither consider project selection nor scheduling, but take into account outsourcing decisions. Finally, in the experimental studies we solve the model with non-linear learning curves as opposed to the linear approximations used in Gutjahr et al. [19].

The remainder of this paper is organized as follows: The following Section 2 introduces an optimization model for the assignment of resources to project work. In Section 3 we describe implementation issues and our test setup. Section 4 presents computational results and gives managerial insights to the impact of different prob- 
lem parameters on the costs, outsourcing decisions and specialization measures of resources and the company. Finally, the paper concludes with a summary and an outlook in Section 5.

\section{Model}

We refer to a work package $(s, t)$ with the demand $r_{s t}$ as the aggregated amount of project work requiring skill $s \in \mathcal{S}$ in period $t=1, \ldots, T$, where $T$ denotes the planning horizon. The pool of resources consists of internal resources $\mathcal{R}^{i}$ and external resources $\mathcal{R}^{e}$, i.e. $\mathcal{R}=\mathcal{R}^{i} \cup \mathcal{R}^{e}$. The demand of work packages requiring skill $s$ can be assigned to resources $k \in \mathcal{R}_{s}=\mathcal{R}_{s}^{i} \cup \mathcal{R}_{s}^{e}$ with cost rates $c_{k t}$ in period $t$. $\mathcal{R}_{s}$ is the set of resources capable of performing project work which requires skill $s$. The set of skills that resource $k$ possesses is denoted with $\mathcal{S}_{k}$. Working times of resources are limited by time-dependent availabilities $R_{k t}$.

The projects are broken up into skill-specific work packages $(s, t)$, which - in contrast to the projects itself - are expected to have a repetitive character. Thus, the related learning process is well-suited to be described by learning curves.

Learning curves are usually monotonically decreasing and convex functions. A learning curve $f_{k s}\left(z_{k s}\right)$ describes the unit production time, i.e. the amount of time that resource $k$ requires to produce one additional unit after having produced $z_{k s}$ units using skill $s$. The number of units $z_{k s}$ produced by resource $k$ in skill $s$ can be interpreted as the experience of the resource w.r.t. the particular skill. We index the function $f_{k s}$ with resource $k$ and skill $s$ since the learning process depends on the type of work $s$ and the abilities of resource $k$ to adapt new knowledge. Furthermore, the argument $z_{k s}$ is also indexed with $k$ and $s$, i.e. we neglect cross-skill or team learning effects.

The time $F_{k s}\left(z_{k s}\right)$ that resource $k$ requires to produce the first $z_{k s}$ units using skill $s$ can be expressed by the integral $F_{k s}\left(z_{k s}\right)=\int_{z^{\prime}=0}^{z_{k s}} f_{k s}\left(z^{\prime}\right) d z^{\prime}$. The time $\tau_{k s}$ required to produce $x_{k s}$ units after having produced $z_{k s}-x_{k s}$ units can then be calculated by $\tau_{k s}=F_{k s}\left(z_{k s}\right)-F_{k s}\left(z_{k s}-x_{k s}\right)$.

We define $z_{k s t}$ as the experience level of resource $k$ in skill $s$ at the end of period $t$. Resource $k$ 's amount of project work performed using skill $s$ in period $t$ is represented by $x_{k s t}$. We model resource $k$ 's amount of depreciated knowledge $\beta_{k s t}$ in skill $s$ as a loss of experience at the beginning of period $t$. Given an initial experience level $z_{k s 0}$ of resource $k$ in skill $s$ at the end of period $t=0, z_{k s t}$ can be calculated by $z_{k s t}=z_{k s(t-1)}-\beta_{k s t}+x_{k s t}$. As stated earlier $\beta_{k s t}$ can depict e.g. forgetting and/or technological progress: For example release dates of new technologies which are known in advance can be modelled due to the index $t$. Using index $s$ the impact on experience can be modelled skill-dependent. E.g. the release of a new programming language might affect programming skills but not database skills. With index $k$ we can discriminate resources w.r.t. their forgetting properties. Note that $z_{k s t}$ can become negative. However, w.l.o.g. $z_{k s t} \geq 0$ can be assured by shifting the learning curve $\sum_{t=1}^{T} \beta_{k s t}$ units to the right and setting $z_{k s 0}:=z_{k s 0}+\sum_{t=1}^{T} \beta_{k s t}$. 
This approach is similar to dynamic inventory models (cf. e.g. Zipkin [43]) with $z_{k s t}$ being the current inventory of knowledge, $\beta_{k s t}$ being the demand or loss of knowledge and $x_{k s t}$ being the ordered and instantaneously delivered (or produced) knowledge.

Strategic goals might require to keep or develop certain skills across the company. To define strategic goals we employ the production possibility frontier (PPF, also known as transformation curve). The PPF is a concave curve describing maximum production quantities for different skills given several (but limited) resources (cf. Varian [36]). Note that in our assignment problem the PPF is not static or given in advance but depends on the actual assignments as it is transformed over time by learning and depreciation of knowledge of human resources. In our model we will not employ requirements on the shape of the complete PPF but only on the values of its intercept points at the axes at the end of the planning horizon. We require the intercept point at axis $s$ to be at least $\phi_{s}$. Thus, the level $\phi_{s}$ is the guaranteed total amount of work per time unit requiring skill $s$ that internal human resources could perform at the end of the planning horizon $T$ if they all used that skill. Figure 1 gives an example for the possible result of the PPF at the end of the planning horizon. A different assignment decision would yield a different PPF. W.r.t. the given values of $\phi_{1}$ and $\phi_{2}$ this solution is feasible, since production rates for both skills could attain level $\phi_{s}$ independently (but not concurrently).

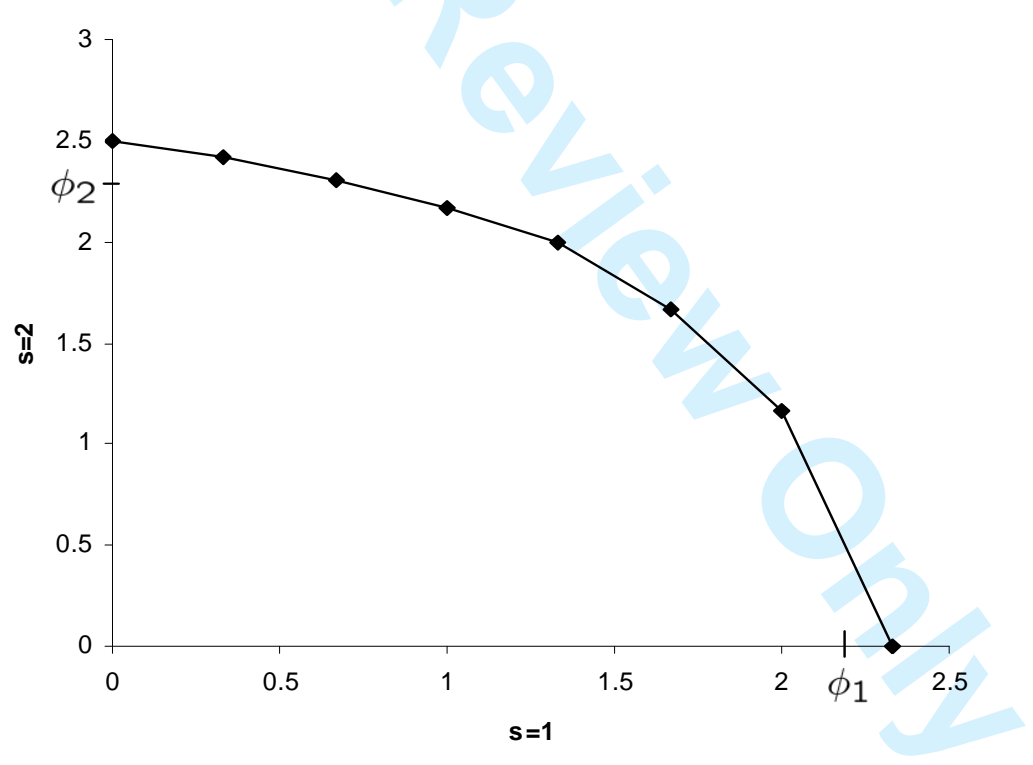

Figure 1: Production possibility frontier

The intercept points of the PPF can be calculated as the sum of production rates of the internal resources with skill $s$ at the end of the planning horizon $T$ defined by

$$
\sum_{k \in \mathcal{R}_{s}^{i}} \frac{1}{f_{k s}\left(z_{k s T}\right)} .
$$


Note that the production rate is the reciprocal of the unit production time calculated by $f_{k s}(\cdot)$.

We model the outlined problem as a non-linear program by employing the following decision variables: The amount of work done by resource $k$ with skill $s$ in period $t$ is denoted with $x_{k s t}$. Resource $k$ 's experience in skill $s$ cumulated up to period $t$ considering depreciation of knowledge is depicted with $z_{k s t}$. Finally, $\tau_{k s t}$ is the time that resource $k$ requires to process the amount of work $x_{k s t}$ of skill $s$ in period $t$.

$$
Z=\operatorname{Min} \sum_{s \in \mathcal{S}} \sum_{k \in \mathcal{R}_{s}} \sum_{t=1}^{T} c_{k t} \cdot \tau_{k s t}
$$

$$
\text { subject to }
$$

$$
z_{k s t}=z_{k s(t-1)}-\beta_{k s t}+x_{k s t}
$$$$
\tau_{k s t}=F_{k s}\left(z_{k s t}\right)-F_{k s}\left(z_{k s t}-x_{k s t}\right)
$$$$
\sum_{k \in \mathcal{R}_{s}^{i}} \frac{1}{f_{k s}\left(z_{k s T}\right)} \geq \phi_{s}
$$$$
\sum_{k \in \mathcal{R}_{s}} x_{k s t} \geq r_{s t}
$$$$
\sum_{s \in \mathcal{S}} \tau_{k s t} \leq R_{k t}
$$$$
x_{k s t}, \tau_{k s t} \geq 0
$$$$
z_{k s t} \in \mathbb{R}
$$

$$
\begin{aligned}
& k \in \mathcal{R}_{s} \\
& s \in \mathcal{S} \\
& t=1, \ldots, T \\
& k \in \mathcal{R}_{s} \\
& s \in \mathcal{S} \\
& t=1, \ldots, T \\
& s \in \mathcal{S} \\
& \\
& s \in \mathcal{S} \\
& t=1, \ldots, T \\
& k \in \mathcal{R} \\
& t=1, \ldots, T \\
& k \in \mathcal{R}_{s} \\
& s \in \mathcal{S} \\
& t=1, \ldots, T \\
& k \in \mathcal{R}_{s} \\
& s \in \mathcal{S} \\
& t=1, \ldots, T
\end{aligned}
$$

The objective function (2) minimizes the costs for performing the work packages $(s, t)$. Constraints $(3)$ are the dynamic experience level constraints, where the experience level $z_{k s t}$ of resource $k$ in skill $s$ at the end of period $t$ is the experience level of the preceding period $(t-1)$ decreased by depreciation of knowledge $\beta_{k s t}$ and increased by the acquisition of knowledge $x_{k s t}$ due to work assignments in period $t$. Constraints (4) calculate the time $\tau_{k s t}$ required to perform $x_{k s t}$ units of work 
package $(s, t)$. Constraints (5) enforce the company skill level targets $\phi_{s}$ at the end of the planning horizon. Constraints (6) ensure that the demand $r_{s t}$ of work package $(s, t)$ is assigned to the resources. Continuous fractional assignment of work packages to resources is allowed. Constraints (7) restrict the availability of the resources. Constraints (8) and (9) define the decision variables.

If there is no learning and no forgetting, model (2)-(9) becomes linear with the learning function $f_{k s}\left(z_{k s}\right)=\frac{1}{\eta_{k s}}$, where $\eta_{k s}$ is the static efficiency of resource $k$ w.r.t. skill $s$ (cf. e.g. Heimerl and Kolisch [21]).

Although the learning functions $f_{k s}\left(z_{k s}\right)$ are assumed to be decreasing and $F_{k s}\left(z_{k s}\right)$ is therefore concave, the model is neither a convex nor a concave optimization problem since constraints (4) calculate the difference of two concave functions resulting in an unclassifiable function.

Note that in Gutjahr et al. [19] the experience ("competence score" in [19]) of resources increases due to the amount of time invested into a skill. In contrast, we assume that the amount of work done by a resource drives its experience which determines the production rate ("efficiency values" in [19]).

\section{Implementation and Test setup}

For our experimental study we employed an adaptation of the exponential learning function (cf. Nembhard and Uzumeri [28], Pendharkar and Subramanian [30]), i.e.

$$
f_{k s}\left(z_{k s}\right)=a_{k s} e^{-\lambda_{k s} z_{k s}}+b_{k s}
$$

and therefore

$$
F_{k s}\left(z_{k s}\right)=\frac{a_{k s}}{\lambda_{k s}}\left(1-e^{-\lambda_{k s} z_{k s}}\right)+b_{k s} z_{k s}
$$

$b_{k s}>0$ represents the steady state unit production time, $\lambda_{k s} \geq 0$ is the learning rate and $a_{k s} \geq 0$ the learning potential of resource $k$ in skill $s$. Note that knowledge depreciation is depicted by $\beta_{k s t}$ in constraints (3) and is therefore implicitly included in the learning curve. We chose this type of learning function due to the ability to depict steady state unit production times and its mathematical tractability. However, the implementation can easily be adapted to other learning functions.

The model was implemented in $\mathrm{C}++$ using Ipopt 3.3.2 of the COIN-OR library (cf. [14]). Ipopt uses a primal-dual interior point filter line search algorithm (cf. Wächter and Biegler [37]) to return an (at least locally) optimal solution. We solved the model 50 times using random starting points in order to partially overcome the lack of only local optimality.

We generated test instances using the base case depicted in Table 1. The values are chosen to obtain realistic small size instances with period lengths of one month and efforts measured in man days. A set of external resources $\mathcal{R}_{s}^{e}$ was taken into account by adding one additional resource with unlimited availabilities for each skill, i.e. $\left|\mathcal{R}_{s}^{e}\right|=1 \forall s$ and $R_{k t}=\infty \forall t, k \in \mathcal{R}_{s}^{e}$. External resources will not be subject to learning nor forgetting and their unit production time is 1, i.e. $a_{k s}=0$ and 
$b_{k s}=1 \forall s, k \in \mathcal{R}_{s}^{e}$. These numbers are based on the assumption that there will always be enough qualified external resources with state-of-the-art knowledge. The costs of external resources depend on the requested skill, and we refer to skill 1 as the cheapest and skill 4 as the most expensive skill.

All six internal resources are capable of performing two out of four skills and each resource has a unique combination of skills. A learning rate of $\lambda_{k s}=0.012$ together with $a_{k s}=0.2$ and $b_{k s}=0.9$ leads to a unit production time of 1 after approximately 60 work units. The parameters of $\left|\mathcal{R}^{i}\right|,\left|\mathcal{S}_{k}\right|, r_{s t}, R_{k t}$ were chosen such that the utilization of internal resources is $150 \%$ if no external resources are employed and all internal resources had static unit production times of 1 , i.e. $f_{k s}(\cdot) \equiv 1$. Furthermore, despite learning effects, the utilization will always be higher than $100 \%$.

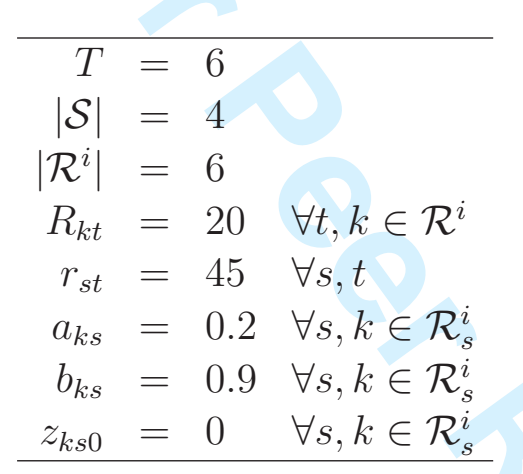

Table 1: Parameters and skill matrix of the base case

We varied four parameters to generate the 16 instances given in Table 2 . The first group of instances $(1-8)$ uses a flat learning curve $\left(\lambda_{k s}=0.012\right)$, the other group (916) uses a steeper learning curve $\left(\lambda_{k s}=0.02\right)$. The shape of the learning curve affects the speed of learning in the sense that resources with a steeper learning curve learn faster. Figure 2 depicts the plots of the learning curves. Within each group some instances $(1-4,9-12)$ neglect forgetting $\left(\beta_{k s t}=0\right)$, the remaining instances impose forgetting $\left(\beta_{k s t}=10\right)$. Some instances $(1-2,5-6,9-10,13-14)$ do not demand company skill level targets $\left(\phi_{s}=0\right)$, while all the other instances do $\left(\phi_{s}>0\right)$. Furthermore, we compare cases with internal costs $c_{k}^{i}=0$ (odd instance numbers) and $c_{k}^{i}=500$ (even instance numbers). For the latter instances internal resources are more expensive than external resources w.r.t. skill $1\left(c_{k}^{i}=500\right.$ vs. $\left.c_{1}^{e}=400\right)$ in case both internal and external resources had equal and horizontal learning curves (i.e. $\left.f_{k s}(\cdot) \equiv 1\right)$. 


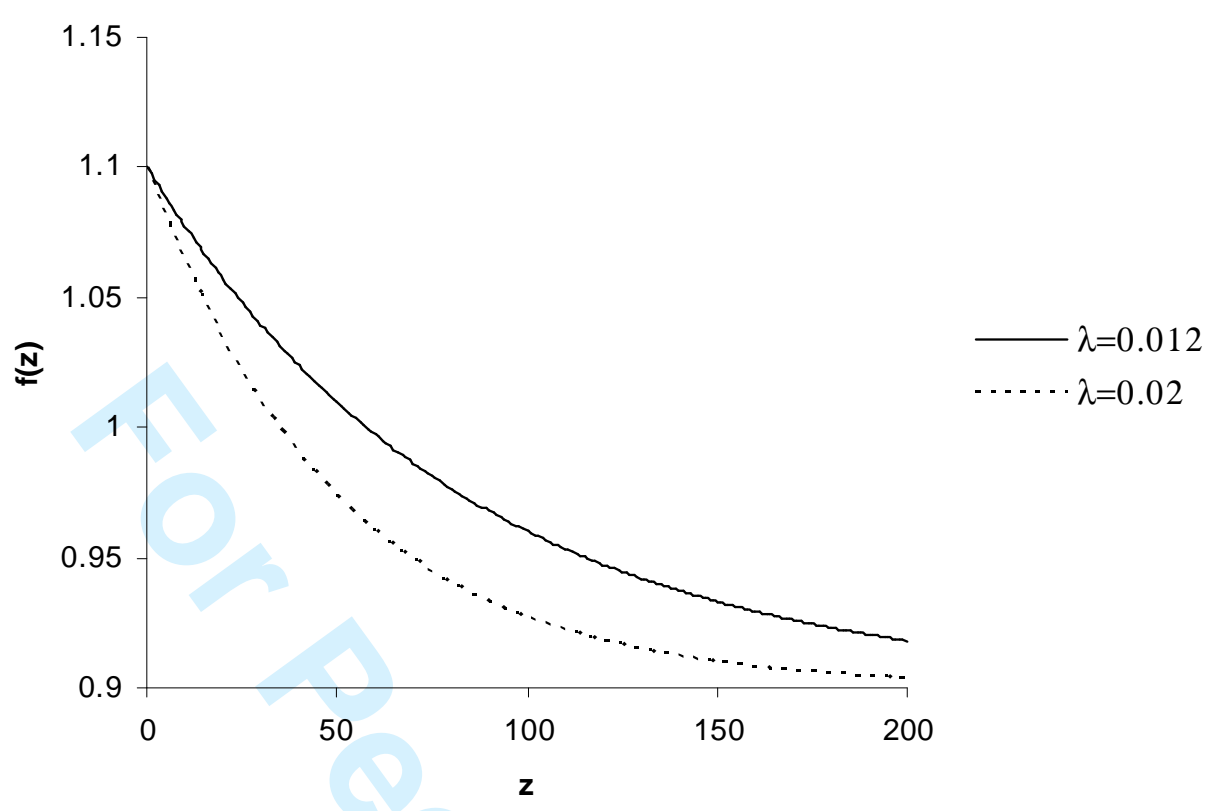

Figure 2: Plots of the flat $(\lambda=0.012)$ and the steep $(\lambda=0.02)$ learning curve $f(z)$

\begin{tabular}{rrrrr}
\hline$\#$ & $\lambda_{k s}$ & $\beta_{k s t}$ & $\phi_{s}$ & $c_{k}^{i}$ \\
\hline \hline 1 & 0.012 & 0 & 0 & 0 \\
2 & 0.012 & 0 & 0 & 500 \\
3 & 0.012 & 0 & 2.8 & 0 \\
4 & 0.012 & 0 & 2.8 & 500 \\
\hline 5 & 0.012 & 10 & 0 & 0 \\
6 & 0.012 & 10 & 0 & 500 \\
7 & 0.012 & 10 & 2.5 & 0 \\
8 & 0.012 & 10 & 2.5 & 500 \\
\hline 9 & 0.02 & 0 & 0 & 0 \\
10 & 0.02 & 0 & 0 & 500 \\
11 & 0.02 & 0 & 3.0 & 0 \\
12 & 0.02 & 0 & 3.0 & 500 \\
\hline 13 & 0.02 & 10 & 0 & 0 \\
14 & 0.02 & 10 & 0 & 500 \\
15 & 0.02 & 10 & 2.25 & 0 \\
16 & 0.02 & 10 & 2.25 & 500 \\
\hline
\end{tabular}

Table 2: Variations of the base case 


\section{Results}

\subsection{Computational results}

The test instances led to a model with 96 variables and 70 constraints. They were solved on a Pentium 4 with $2.4 \mathrm{GHz}$ and $1.5 \mathrm{~GB}$ RAM. We recorded the required time to solve 50 random starting point problems (cf. Table 3). For the instances given in Table 2 the solution time is 21 seconds on average and always less than 33 seconds. The instances with internal costs $c_{k}^{i}=500$ are harder to solve than those with $c_{k}^{i}=0$ (24.6 vs. 17.0 seconds). This is probably due to the fact that the full utilization of internal resources is not always an optimal solution in cases where $c_{k}^{i}=500$ and thus constraints (7) are not always binding.

The benefit of using random starting points is measured using the average and maximum deviation of different starting point solutions to the best solution found. For 5 out of 16 instances (31\%) the use of random starting points led to no improvements. On the other hand, the average distance from the locally optimal solutions to the best solutions found was $0.24 \%$ and the maximum distance was $8.3 \%$. Thus, for some instances choosing a good starting point matters and random starting points are a straight-forward strategy to find a good solution.

\begin{tabular}{rrrrr}
\hline$\#$ & time $[\mathrm{sec}]$ & best & avg dev $\%$ & max dev $\%$ \\
\hline 1 & 13.5 & 159,164 & 0.00 & 0.00 \\
2 & 21.8 & 516,994 & 0.06 & 0.18 \\
3 & 18.1 & 163,787 & 0.00 & 0.00 \\
4 & 24.9 & 523,407 & 0.00 & 0.02 \\
5 & 17.9 & 177,638 & 0.06 & 1.38 \\
6 & 32.7 & 531,690 & 0.00 & 0.00 \\
7 & 18.7 & 191,577 & 0.35 & 2.07 \\
8 & 23.6 & 551,577 & 0.11 & 0.55 \\
9 & 14.8 & 147,619 & 0.13 & 0.14 \\
10 & 18.1 & 506,487 & 0.18 & 0.26 \\
11 & 14.0 & 168,480 & 0.00 & 0.00 \\
12 & 17.4 & 528,480 & 0.00 & 0.00 \\
13 & 18.5 & 173,990 & 0.60 & 8.30 \\
14 & 30.6 & 527,117 & 0.72 & 1.85 \\
15 & 20.3 & 182,632 & 1.45 & 3.52 \\
16 & 27.7 & 542,631 & 0.23 & 0.91 \\
\hline mean & 20.8 & 349,579 & 0.24 & 1.20 \\
\hline
\end{tabular}

Table 3: Computational results

In order to analyze the limits of the Ipopt-algorithm we additionally employed larger instances as given in Table 4 . The instances are based on instance \#1 given in Table 2, where the number of resources $\left|\mathcal{R}^{i}\right|$ and skills $|\mathcal{S}|$ has been increased and 
two random skills were assigned to each resource. For each combination of $\left|\mathcal{R}^{i}\right|$ and $|\mathcal{S}|$ we generated 5 test instances. The results are given in Table 4 . Obviously, even large instances with 100 resources and 50 skills can be solved within minutes using the 50 random starting points approach. However, the solutions did not benefit from the use of random starting points.

\begin{tabular}{rrrr}
\hline$\left|\mathcal{R}^{i}\right|$ & $|\mathcal{S}|$ & avg. time $[\mathrm{sec}]$ & max dev \% \\
\hline 25 & 10 & 45.5 & 0.00 \\
50 & 25 & 110.7 & 0.00 \\
100 & 50 & 494.5 & 0.00 \\
\hline
\end{tabular}

Table 4: Additional computational results

\subsection{Managerial insights}

\subsubsection{Analysis methods}

To gain managerial insights the results are analysed on the individual level of a resource and on the aggregate level of the company, in which the values of all internal resources are summed up. Let

$$
x_{k s}^{\mathcal{R}}=\sum_{t} x_{k s t}
$$

be the amount of work done by resource $k$ for skill $s$ during the entire planning horizon and let

$$
x_{s}^{\mathcal{C}}=\sum_{k \in \mathcal{R}^{i}} x_{k s}^{\mathcal{R}}
$$

be the amount of work done by internal (company) resources for skill $s$ during the planning horizon, then

$$
\rho_{s}=\frac{x_{s}^{\mathcal{C}}}{\sum_{t} r_{s t}}
$$

is the fraction of work $\rho_{s}$ done by internal resources for skill $s$ during the planning horizon. We use $\rho_{s}$ to analyse outsourcing decisions. Further let

$$
X_{k}^{\mathcal{R}}=\left\{x_{k 1}^{\mathcal{R}}, x_{k 2}^{\mathcal{R}}, x_{k 3}^{\mathcal{R}}, \ldots\right\}
$$

and

$$
X^{\mathcal{C}}=\left\{x_{1}^{\mathcal{C}}, x_{2}^{\mathcal{C}}, x_{3}^{\mathcal{C}}, \ldots\right\}
$$

be sets that combine the data points of the different skills. The coefficient of variation

$$
\operatorname{CV}\left(X^{\mathcal{C}}\right)=\frac{\sqrt{\operatorname{VAR}\left(X^{\mathcal{C}}\right)}}{\mathrm{E}\left(X^{\mathcal{C}}\right)}
$$


gives an indication about the specialization of the company: A high coefficient of variation indicates high specialization of the company, since the assignment of internal resources to work packages of different skills is very unequal, i.e. high for some skills, low for others. The values of $\rho_{s}$ and $\mathrm{CV}\left(X^{\mathcal{C}}\right)$ for the solutions of the instances are listed in Table 5.

The specialization of individual resource $k \in \mathcal{R}^{i}$ can be measured with

$$
\bar{\sigma}_{k}=\frac{\sigma_{k}}{\sigma_{k}^{\max }}
$$

which uses the standard deviation

$$
\sigma_{k}=\sqrt{\operatorname{VAR}\left(X_{k}^{\mathcal{R}}\right)}=\sqrt{\mathrm{E}\left(\left(X_{k}^{\mathcal{R}}\right)^{2}\right)-\left(\mathrm{E}\left(X_{k}^{\mathcal{R}}\right)\right)^{2}}=\sqrt{\frac{\sum_{s}\left(x_{k s}^{\mathcal{R}}\right)^{2}}{\left|\mathcal{S}_{k}\right|}-\left(\frac{\sum_{s} x_{k s}^{\mathcal{R}}}{\left|\mathcal{S}_{k}\right|}\right)^{2}}
$$

and is normalized with the maximum possible standard deviation $\sigma_{k}^{\max } \cdot \sigma_{k}^{\max }$ can be determined by calculating $\sigma_{k}$ if only one skill is used as much as possible. If all skills are used equally by resource $k$, i.e. $x_{k s}^{\mathcal{R}}=x_{k s^{\prime}}^{\mathcal{R}} \forall s, s^{\prime}$, we obtain $\bar{\sigma}_{k}=0$. If only one skill is used, $\bar{\sigma}_{k}=1$ holds. The values for the specialization $\bar{\sigma}_{k}$ are also listed in Table 5.

\begin{tabular}{r|rrrrr|rrrrrrr}
\hline$\#$ & $\rho_{1}$ & $\rho_{2}$ & $\rho_{3}$ & $\rho_{4}$ & $\mathrm{CV}\left(X^{\mathcal{C}}\right)$ & $\bar{\sigma}_{1}$ & $\bar{\sigma}_{2}$ & $\bar{\sigma}_{3}$ & $\bar{\sigma}_{4}$ & $\bar{\sigma}_{5}$ & $\bar{\sigma}_{6}$ & avg. \\
\hline 1 & 0.00 & 0.62 & 1.00 & 1.00 & 0.156 & 1.00 & 1.00 & 1.00 & 1.00 & 0.37 & 0.48 & 0.81 \\
2 & 0.00 & 0.44 & 1.00 & 1.00 & 0.172 & 1.00 & 1.00 & 1.00 & 1.00 & 1.00 & 0.17 & 0.86 \\
3 & 0.16 & 0.46 & 1.00 & 1.00 & 0.138 & 1.00 & 1.00 & 0.40 & 1.00 & 0.92 & 0.48 & 0.80 \\
4 & 0.16 & 0.16 & 1.00 & 1.00 & 0.180 & 0.03 & 1.00 & 1.00 & 1.00 & 1.00 & 0.17 & 0.70 \\
5 & 0.00 & 0.48 & 1.00 & 1.00 & 0.167 & 1.00 & 1.00 & 1.00 & 0.68 & 1.00 & 0.21 & 0.82 \\
6 & 0.00 & 0.00 & 1.00 & 1.00 & 0.250 & 0.00 & 1.00 & 1.00 & 1.00 & 1.00 & 0.11 & 0.68 \\
7 & 0.31 & 0.36 & 0.81 & 1.00 & 0.117 & 0.84 & 0.91 & 0.21 & 1.00 & 1.00 & 1.00 & 0.83 \\
8 & 0.31 & 0.36 & 0.81 & 1.00 & 0.117 & 0.84 & 0.91 & 0.21 & 1.00 & 1.00 & 1.00 & 0.83 \\
9 & 0.00 & 0.81 & 0.91 & 1.00 & 0.146 & 1.00 & 1.00 & 1.00 & 1.00 & 0.64 & 1.00 & 0.94 \\
10 & 0.00 & 0.46 & 1.00 & 1.00 & 0.170 & 1.00 & 1.00 & 1.00 & 1.00 & 1.00 & 0.20 & 0.87 \\
11 & 0.39 & 0.47 & 0.81 & 1.00 & 0.092 & 0.22 & 0.56 & 0.41 & 1.00 & 0.15 & 1.00 & 0.56 \\
12 & 0.39 & 0.47 & 0.81 & 1.00 & 0.092 & 0.33 & 0.57 & 0.41 & 1.00 & 0.15 & 1.00 & 0.58 \\
13 & 0.00 & 0.68 & 0.86 & 1.00 & 0.151 & 1.00 & 1.00 & 1.00 & 1.00 & 0.30 & 1.00 & 0.88 \\
14 & 0.00 & 0.00 & 0.98 & 1.00 & 0.250 & 0.00 & 1.00 & 1.00 & 1.00 & 1.00 & 0.24 & 0.71 \\
15 & 0.28 & 0.40 & 0.86 & 1.00 & 0.120 & 0.91 & 1.00 & 0.30 & 1.00 & 1.00 & 1.00 & 0.87 \\
16 & 0.27 & 0.30 & 0.86 & 1.00 & 0.134 & 0.83 & 1.00 & 0.27 & 1.00 & 1.00 & 1.00 & 0.85 \\
\hline
\end{tabular}

Table 5: Fraction $\rho_{s}$ of work done internally, specialization of the company $\mathrm{CV}\left(X^{\mathcal{C}}\right)$ and specialization $\bar{\sigma}_{k}$ of internal resources

In addition, we visualize the assignment of work packages to internal resources over time on the company level as in Figure 3(a). The work done by all internal resources $\left(\sum_{k \in \mathcal{R}^{i}} x_{k s t}\right)$ is shown on the ordinate while the time line is on the abscissa. The four skills are represented by four different curves. For example in Figure 3(a) 
skill 1 is not done internally at all while the amount of work that is done internally for skill 2 increases with each period. Note that the curves for skill 3 and 4 are super-imposed at a maximum of $\sum_{k \in \mathcal{R}^{i}} x_{k 3 t}=\sum_{k \in \mathcal{R}^{i}} x_{k 4 t}=45$.

Figure $3(\mathrm{~b})$ depicts the assignments on an individual level. Each subdiagram shows the assignments of work requiring one skill to the resources. The work done by internal resources is shown as stacked bars on the ordinate while the time line is on the abscissa. For example in Figure 3(b) the top right subdiagram depicts skill 2. The work requiring that skill is done by resource 1 and furthermore by resource 5 in a growing amount. The height of the stacked bars correspond to the strictly monotone increasing curve for skill 2 in Figure 3(a).

\subsubsection{Outsourcing decisions}

As stated in Section 3, due to the chosen problem parameters, the average utilization of the internal resources is higher than $100 \%$. Therefore, it is not possible to do all the work internally. From Table 5 we can observe that, in general, those work packages are outsourced (low values of $\rho_{1}$ and $\rho_{2}$ ) which require cheap skills, i.e. a skill $s$ that can be outsourced at relatively low $\operatorname{costs} c_{s}^{e}$. On the other hand work packages which require expensive skills are (almost) completely done internally ( $\rho_{3}$ and $\rho_{4}$ close or equal to 1 ). As expected, the inequality $\rho_{s} \geq \rho_{s^{\prime}}$ holds if $c_{s}^{e}>c_{s^{\prime}}^{e}$.

\subsubsection{Impact of the shape of the learning curve}

Impact on the company When comparing instances 1 and 5 with its counterparts 9 and 13 that have a steeper learning curve, we can see that a steeper learning curve leads to a broader qualification of the company, since $\operatorname{CV}\left(X^{\mathcal{C}}\right)$ in Table 6 is lower for instances 9 and 13. This holds regardless of the depreciation of knowledge.

\begin{tabular}{rrr|rrrrr}
\hline$\#$ & $\lambda_{k s}$ & $\beta_{k s t}$ & $\rho_{1}$ & $\rho_{2}$ & $\rho_{3}$ & $\rho_{4}$ & $\mathrm{CV}\left(X^{\mathcal{C}}\right)$ \\
\hline 1 & 0.012 & 0 & 0.00 & 0.62 & 1.00 & 1.00 & 0.156 \\
5 & 0.012 & 10 & 0.00 & 0.48 & 1.00 & 1.00 & 0.167 \\
9 & 0.02 & 0 & 0.00 & 0.81 & 0.91 & 1.00 & 0.146 \\
13 & 0.02 & 10 & 0.00 & 0.68 & 0.86 & 1.00 & 0.151 \\
\hline
\end{tabular}

Table 6: Fraction $\rho_{s}$ of work done internally and specialization of the company $\mathrm{CV}\left(X^{\mathcal{C}}\right)$ for instances $1,5,9$ and 13

Figure 3(a) which graphically shows the solution for instance 1 illustrates this finding. Skill 3 and 4 are completely done by internal resources $\left(\sum_{k \in \mathcal{R}^{i}} x_{k s t}=r_{s t}=\right.$ $45)$, skill 1 is completely outsourced $\left(\sum_{k \in \mathcal{R}^{i}} x_{k s t}=0\right)$ and the amount of work that is done internally for skill 2 increases over time. The increase of internal work for skill 2 can be explained with the four diagrams shown in Figure 3(b). It stems from the efficiency gains of resources 3 and 6 , that enable resource 5 to use more of its capacity performing skill 2. Furthermore, resources 5 and 1 are becoming more efficient in doing skill 2 as well. 


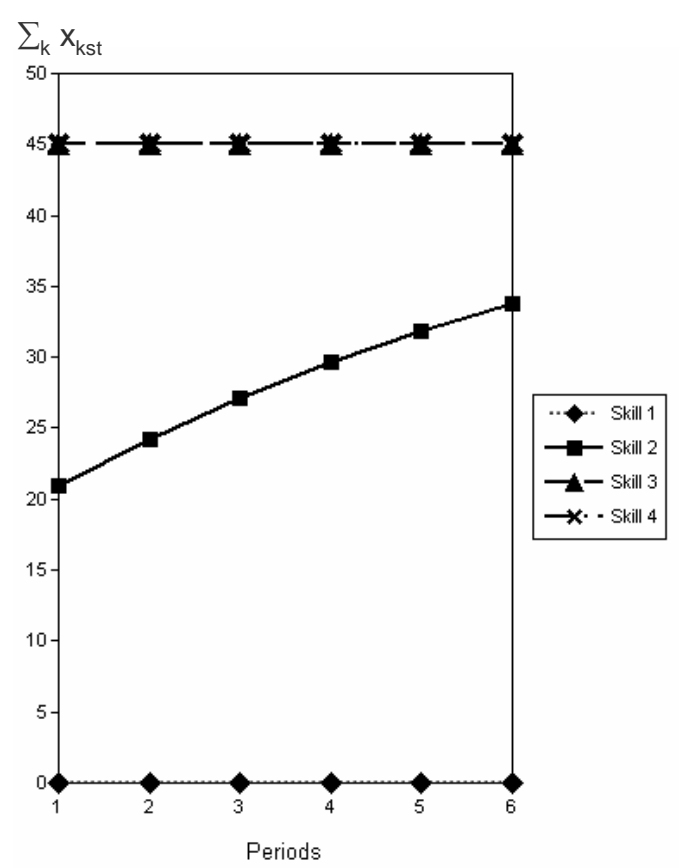

(a) company level

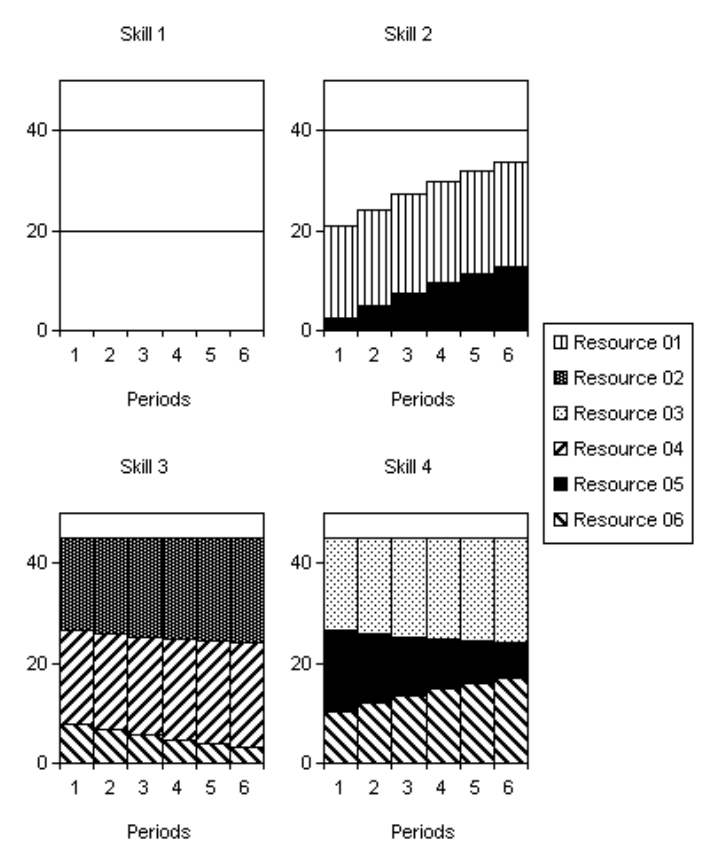

(b) individual level

Figure 3: Solution of instance 1 with $\lambda_{k s}=0.012, \phi_{s}=0, \beta_{k s t}=0$, and $c_{k}^{i}=0$

At first sight it seems that the following greedy heuristic would provide optimal results: i) Order work packages in decreasing order of external skill costs. ii) Beginning with the work package requiring the most expensive external skill, assign work packages to available internal resources as long as possible. iii) Outsource the remaining work. However, Figure 4(a) gives a counterexample. The figure shows the solution for instance 9 which, compared to instance 1, has a steeper learning curve. The difference compared to instance 1 is that some of the work for the more expensive skill 3 has been outsourced $\left(\sum_{k \in \mathcal{R}^{i}} x_{k s t}<r_{s t}=45\right)$ in favour of skill 2 which is now done more intensively by internal resources and less outsourced. The reason for this phenomenon can be examined using Figure 4(b) which reveals that the full dedication of resources 2 and 4 to skill 3 and resource's 5 higher dedication to skill 2 leads to lower overall costs.

Impact on individual resources The impact of the learning curve's shape on the individual resources can be examined with a comparison of $\bar{\sigma}_{k}$ for instances 1 and 5 with its counterparts 9 and 13 in Table 7 . Regarding these four instances a steeper learning curve seems to lead to more specialized individual resources since $\bar{\sigma}_{k}$ is higher on average. These numbers are supported by the fact that there are 4 fully specialized resources $\left(\bar{\sigma}_{k}=1\right)$ in instance 1 while there are 5 of them in instance 9 . Resource 5 (with skills 2 and 4 ) and resource 6 (with skills 3 and 4 ) are both capable of performing skill 4, while skill 2 (the other skill of resource 5) is cheaper than skill 3 (the other skill of resource 6) (cf. Table 1). Therefore, one 


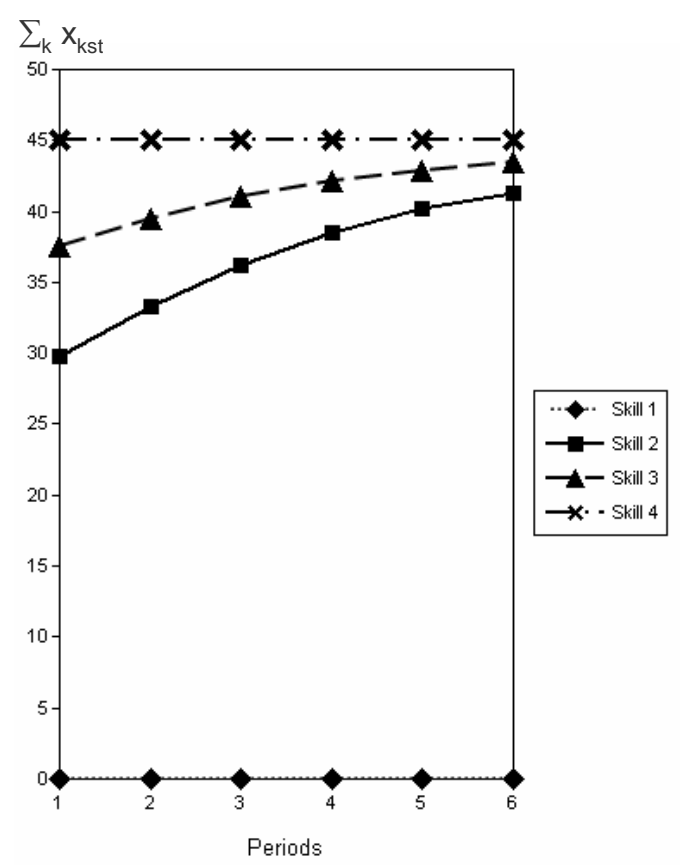

(a) company level

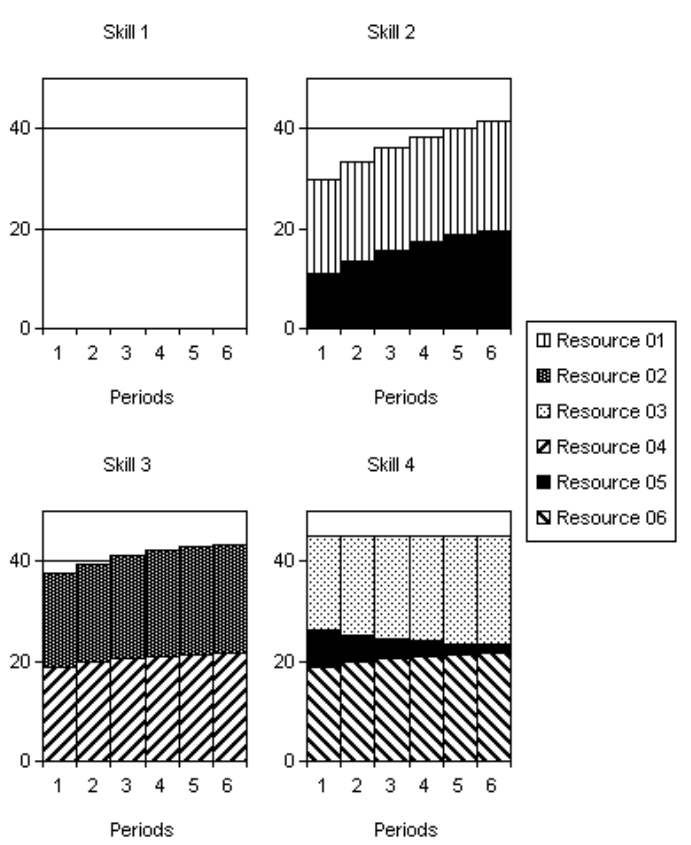

(b) individual level

Figure 4: Solution of instance 9 with $\lambda_{k s}=0.02, \phi_{s}=0, \beta_{k s t}=0$, and $c_{k}^{i}=0$

would expect that resource 5 (with the cheaper other skill) is devoted to perform skill 4 rather than resource 6 (with the more expensive other skill). However, in instance 9 resource 5 is qualified for both skills while resource 6 is fully specialized for skill 4. This contradicts the intuition that a higher difference of skill values (as for resource 5) should lead to a stricter specialization for the more expensive skill.

\begin{tabular}{rrr|rrrrrrr}
\hline$\#$ & $\lambda_{k s}$ & $\beta_{k s t}$ & $\bar{\sigma}_{1}$ & $\bar{\sigma}_{2}$ & $\bar{\sigma}_{3}$ & $\bar{\sigma}_{4}$ & $\bar{\sigma}_{5}$ & $\bar{\sigma}_{6}$ & avg. \\
\hline 1 & 0.012 & 0 & 1.00 & 1.00 & 1.00 & 1.00 & 0.37 & 0.48 & 0.81 \\
5 & 0.012 & 10 & 1.00 & 1.00 & 1.00 & 0.68 & 1.00 & 0.21 & 0.82 \\
9 & 0.02 & 0 & 1.00 & 1.00 & 1.00 & 1.00 & 0.64 & 1.00 & 0.94 \\
13 & 0.02 & 10 & 1.00 & 1.00 & 1.00 & 1.00 & 0.30 & 1.00 & 0.88 \\
\hline
\end{tabular}

Table 7: Specialization $\bar{\sigma}_{k}$ of internal resources for instances 1, 5, 9 and 13

The numbers disclose that the specialization measures on the individual and company level diverge. A steeper learning curve leads to more specialized individual resources in terms of $\sigma_{k}$ but a broader qualified company in terms of $\operatorname{CV}\left(X^{\mathcal{C}}\right)$.

\subsubsection{Impact of company skill level targets}

Company skill level targets broaden the company's qualification. This can be seen by comparing the coefficients of variation $\mathrm{CV}\left(X^{\mathcal{C}}\right)$ of instances 1 and $3(0.156$ 
vs. 0.138$), 5$ and 7 (0.167 vs. 0.117$), 9$ and 11 (0.146 vs. 0.092), as well as 13 and 15 (0.151 vs. 0.120$)$ in Table 5 , respectively. The proposition is also supported by comparison of Figures 3(a) and 5(a). We can clearly see that in the latter figure the cheapest skill 1 is used and trained to reach the required company skill level targets of $\phi_{s}=2.8$ for all skills, while it is completely outsourced in Figure 3(a). In order to reach this goal less work of skill 2 is done by internal resources which in turn leads to a higher amount of outsourced work demanding this skill.

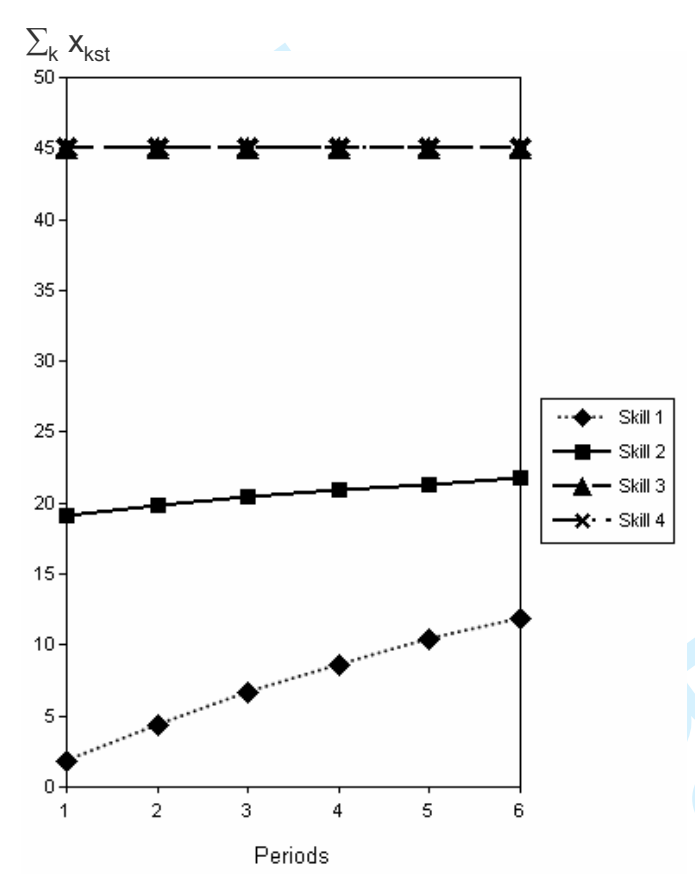

(a) company level

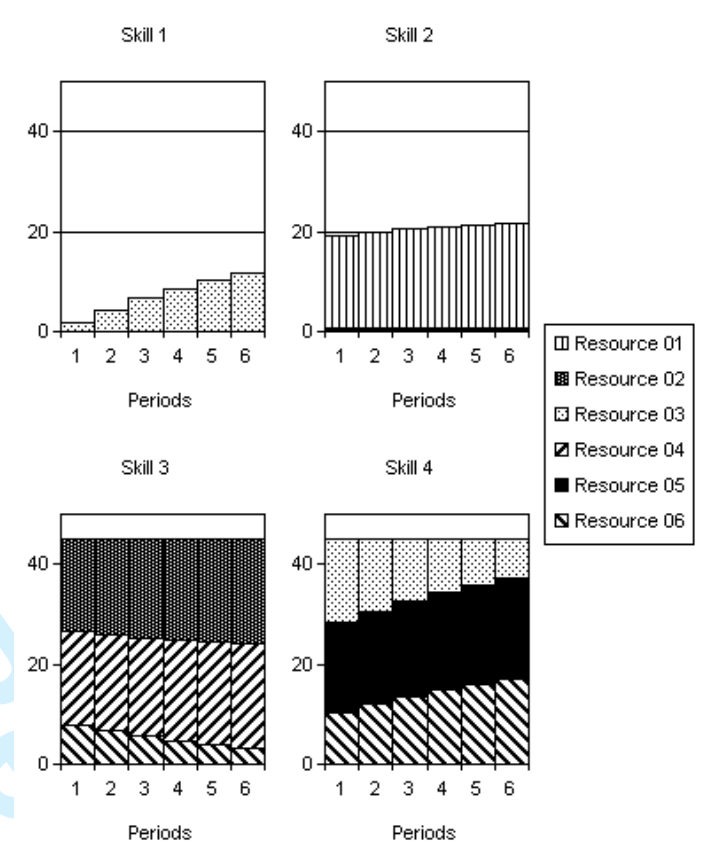

(b) individual level

Figure 5: Solution of instance 3 with $\lambda_{k s}=0.012, \phi_{s}=2.5, \beta_{k s t}=0$, and $c_{k}^{i}=0$

Of course, increasing company skill level targets $\phi_{s}$ lead to higher overall costs since the solution space is reduced due to constraints (5). Due to the different shapes of the learning curves the company skill level targets $\phi_{s}$ are hardly comparable in a quantitative manner. Therefore, Figure 6 depicts the dependence of the costs on the company skill level targets for further variations of instance 1 with a flat learning curve. For $\phi_{s} \geq 3$ no feasible solutions could be found.

\subsubsection{Impact of knowledge depreciation}

We observed basically similar results comparing instances 1 and 5 as well as 9 and 13. No structural difference on the company level between the solutions of different levels of knowledge depreciation can be identified for instances with company skill level targets $\phi_{s}=0$ : As can be seen in Figure 3(a) and Figure 7(a), expensive skills are done completely internally while cheap skills are outsourced. On the individual level, however, the assignments of work to resources shift. Of course, the fraction 


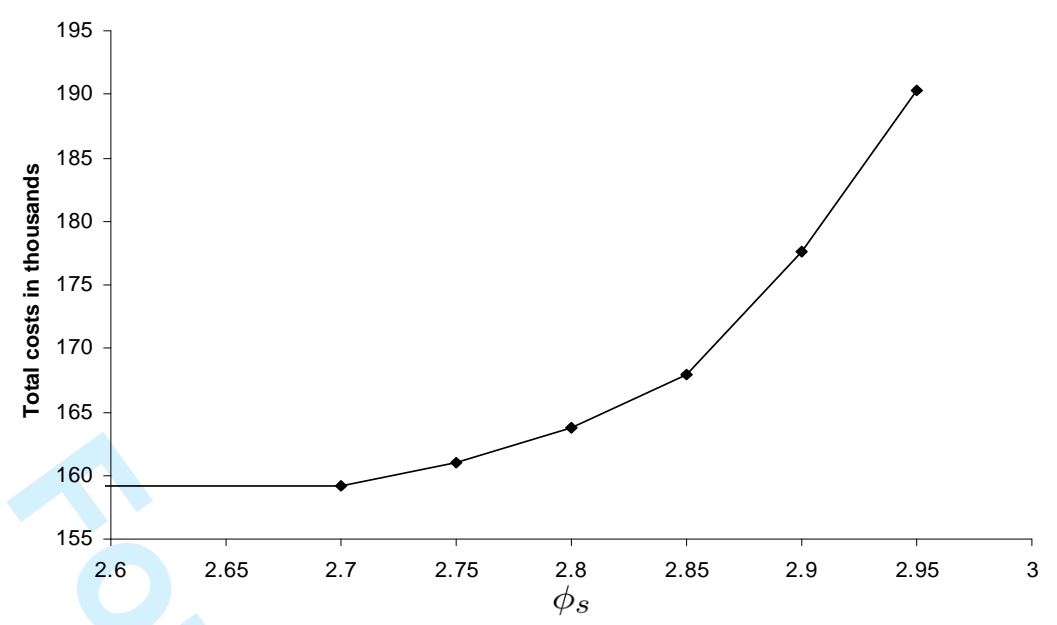

Figure 6: Influence of company skill level targets $\phi_{s}$ on costs

of work $\rho_{s}$ that can be done internally decreases with the amount of knowledge depreciation. As a consequence costs increase by more than $10 \%$ (cf. Table 3). No particular impact of the influence of knowledge depreciation on specialization measures $\mathrm{CV}\left(X^{\mathcal{C}}\right)$ and $\bar{\sigma}_{k}$ can be observed.

We illustrate the combined effects of knowledge depreciation and synchronously imposed company skill level targets $\phi_{s}=2.5$ by Figure $8(\mathrm{a})$ which shows the results for instance 7 . As before, assignment in decreasing order of external skill costs is basically still reasonable. But as it has been observed for the case of company skill level targets without knowledge depreciation, the amount of work for skill 1 done by internal resources must be non-zero.

It is noteworthy that, in order to reach a company skill level target in constraints (5), only the cumulated amount of work done in that skill is important. This is due to constraints (3) in which depreciation of knowledge is a subtractive term. Thus, it is a constant at the end of planning horizon regardless of the assignment decisions. Therefore, scheduling of work package assignments is irrelevant for reaching company skill level targets $\phi_{s}$. In fact, scheduling of the work package assignments is only important for the objective function (2). In case of knowledge depreciation and company skill level targets the solutions do not only depend on the assignment decisions (i.e. who does what) alone but on the time line of assignments (i.e. scheduling, who does what in which period) as well. The decision of doing a skill rather in the beginning or in the end of the planning horizon in order to reach company skill level targets at minimum costs is obviously important. If an amount $r_{s}$ of work has to be done in one single period $t$ by resource $k$ subject to knowledge depreciation, it can be done in less time in period $t=1\left(\right.$ when $\left.f_{k s}(\cdot)=f_{k s}\left(z_{k s 0}\right)\right)$ than in period $t=T$ (when $f_{k s}(\cdot) \gg f_{k s}\left(z_{k s 0}\right)$ due to knowledge depreciation). In this context, it makes sense that in Figure 8(b) resource 3 is completely dedicated to skill 1 during the entire planning horizon while resources 1 and 2 perform skill 1 only in the first periods to reach the company skill level targets. 


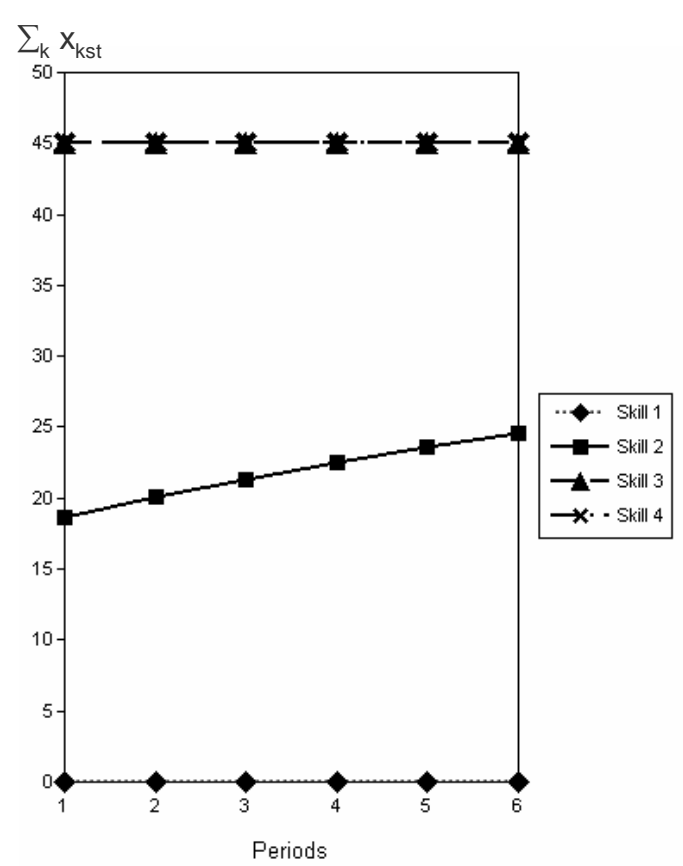

(a) company level
Skill 1

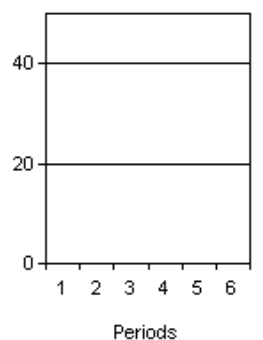

Skill 3

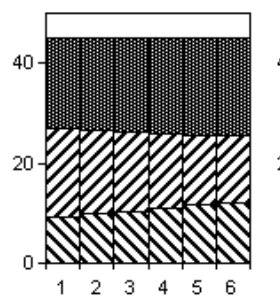

Periods
Skill 2

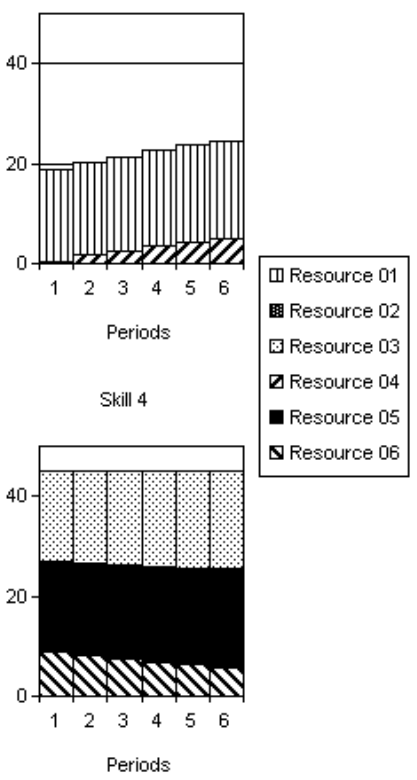

(b) individual level

Figure 7: Solution of instance 5 with $\lambda_{k s}=0.012, \phi_{s}=0, \beta_{k s t}=10$, and $c_{k}^{i}=0$

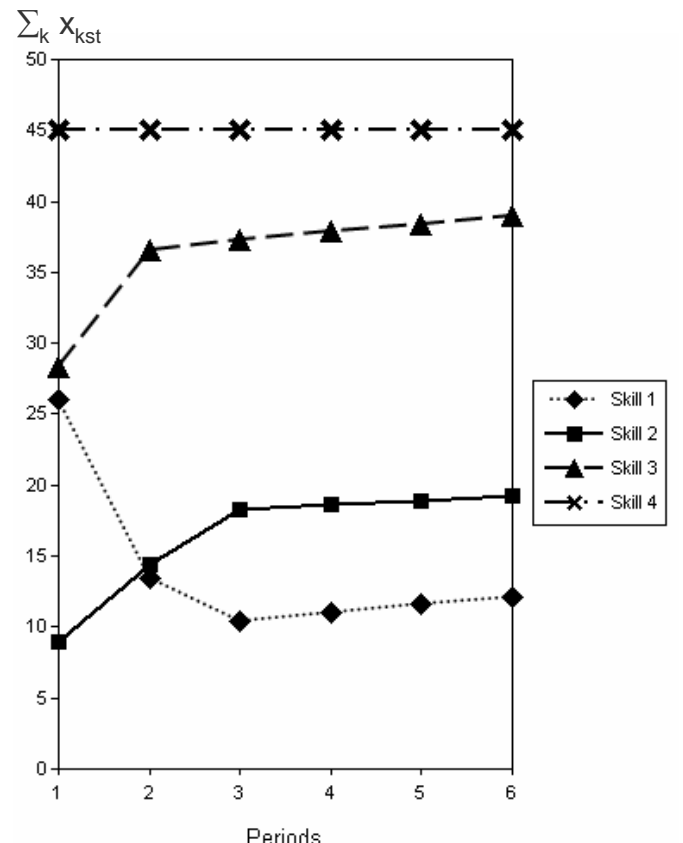

(a) company level
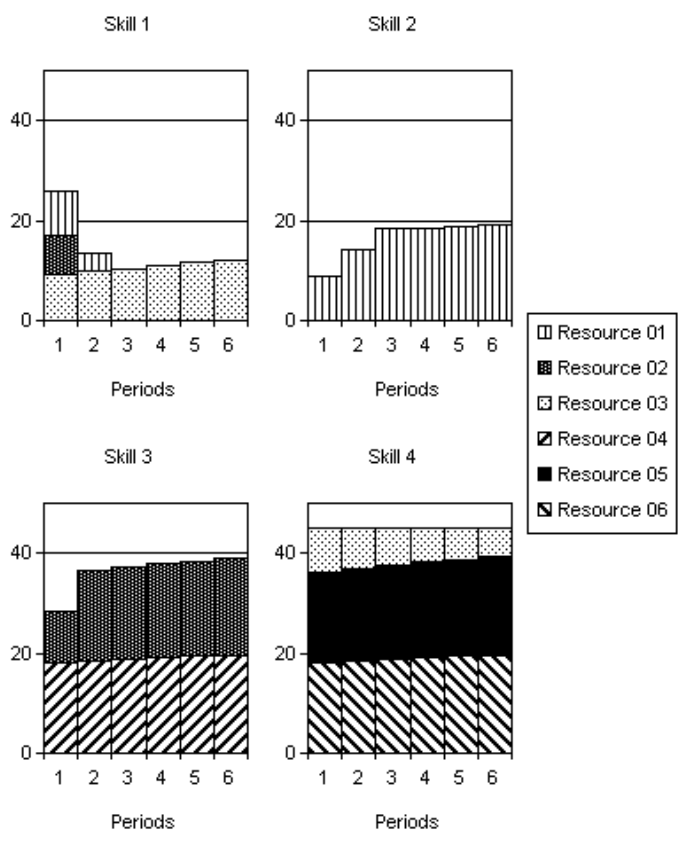

(b) individual level

Figure 8: Solution of instance 7 with $\lambda_{k s}=0.012, \phi_{s}=2.5, \beta_{k s t}=10$, and $c_{k}^{i}=0$ 


\subsubsection{Impact of internal costs}

With costs of $c_{k}^{i}=500$ the allocation of internal resources to cheap skills $\left(c_{1}^{e}=400\right)$ is avoided, even if internal resources are not completely utilized. For the parameters of the relevant test instances internal resources cannot compete with external resources in terms of costs for skill 1 and 2 despite learning effects. This can be seen in the results when comparing $\rho_{s}$ of odd instance numbers $\left(c_{k}^{i}=0\right)$ with the values of even instance numbers $\left(c_{k}^{i}=500\right)$. However, in order to reach company skill level targets $\phi_{s}>0$ in instances 4, 8, 12 and 16 the assignment of relatively expensive internal resources for these skills is mandatory.

\section{Conclusions and Outlook}

In this paper we presented a constrained non-linear continuous optimization model to address the problem of cost-minimal assignment of project work to internal and external multi-skilled human resources. The effects of learning and depreciation of knowledge as well as the goal of reaching company skill level targets at the end of the planning horizon are taken into account.

Our results show that our heuristic implementation has a promising computational performance. The use of random starting points improved the quality of the solutions significantly for some instances.

We analysed the solutions w.r.t. the influence of problem parameters. For selected parameter combinations the intuition is supported that externally expensive skills should be done by internal resources while cheaper skills should be outsourced. However, several observations showed that an implementation of this policy as a greedy assignment heuristic will not provide optimal results. Furthermore, we found out that the shape of the learning curve leads to different qualification strategies which depend on the level of analysis: Faster learning makes human resources more specialized which paradoxically leads to a broader qualification of the company. Company skill level targets are an effective tool to broaden the qualification of the company but they can induce high costs. Due to the objective of cost-minimization, depreciation of knowledge together with company skill level targets cause assignment decisions to depend on the time line (i.e. scheduling): Skills which are less expensive when outsourced are used more intensively by internal resources in the beginning than in the end of the planning horizon in order to minimize costs.

Further research could compare our random starting point approach with a more sophisticated selection of starting points which ensures diversification. Furthermore, other global search techniques like e.g. genetic algorithms might also be well-suited to solve the problem. The fractional assignment decisions could be coded as a string and their fitness can then be evaluated easily (cf. Yoshimura et al. [42]). Finally, the problem could be extended to include project scheduling decisions in order to facilitate the possibility of demand levelling. 


\section{References}

[1] N. Abboud, M. Inuiguchi, M. Sakawa, and Y. Uemura. Manpower allocation using genetic annealing. European Journal of Operational Research, 111(2): 405-420, Dec. 1998.

[2] E. Alba and F. J. Chicano. Software project management with GAs. Information Sciences, 177(11):2380-2401, June 2007.

[3] Y. Arzi and A. Shtub. Learning and forgetting in mental and mechanical tasks: A comparative study. IIE Transactions, 29(9):759-768, 1997.

[4] D. P. Ballou and G. K. Tayi. A decision aid for the selection and scheduling of software maintenance projects. IEEE Transactions on Systems, Man, and Cybernetics - Part A: Systems and Humans, 26(2):203-212, 1996.

[5] M. Bassett. Assigning projects to optimize the utilization of employees' time and expertise. Computers \& Chemical Engineering, 24(2-7):1013-1021, July 2000.

[6] O. Bellenguez and E. Néron. Lower bounds for the multi-skill project scheduling problem with hierarchical levels of skills. Lecture Notes on Computer Sciences, 3616:229-243, 2005.

[7] R. Bhatnagar, V. Saddikutti, and A. Rajgopalan. Contingent manpower planning in a high clock speed industry. International Journal of Production Research, 45(9):2051-2072, May 2007.

[8] W. F. Boh, S. A. Slaughter, and J. A. Espinosa. Learning from experience in software development: A multilevel analysis. Management Science, 53(8): 1315-1331, Aug. 2007.

[9] M. J. Brusco. An exact algorithm for a workforce allocation problem with application to an analysis of cross-training policies. IIE Transactions, 40(5): 495-508, May 2008.

[10] X. Cai and K. Li. A genetic algorithm for scheduling staff of mixed skills under multi-criteria. European Journal of Operational Research, 125(2):359$369,2000$.

[11] G. M. Campbell and M. Diaby. Development and evaluation of an assignment heuristic for allocating cross-trained workers. European Journal of Operational Research, 138(1):9-20, Apr. 2002.

[12] A. N. K. Chen and T. M. Edgington. Assessing value in organizational knowledge creation: Considerations for knowledge workers. MIS Quarterly, 29(2): 279-309, June 2005. 
[13] S. C. Chu and C. K. Lin. A manpower allocation model of job specialization. Journal of the Operational Research Society, 44(10):983-989, Oct. 1993.

[14] Coin-OR. http://www.coin-or.org/projects/Ipopt.xml.

[15] A. Corominas, J. Ojeda, and R. Pastor. Multi-objective allocation of multifunction workers with lower bounded capacity. Journal of the Operational Research Society, 56(6):738-743, Nov. 2005.

[16] A. Corominas, R. Pastor, and E. Rodriguez. Rotational allocation of tasks to multifunctional workers in a service industry. International Journal of Production Economics, 103(1):3-9, Sept. 2006.

[17] H. Eiselt and V. Marianov. Employee positioning and workload allocation. Computers $\&$ Operations Research, 35(2):513-524, Feb. 2008.

[18] W. J. Gutjahr and P. Reiter. Bi-objective project portfolio selection and staff assignment under uncertainty. Technical report, Universität Wien, 2008.

[19] W. J. Gutjahr, S. Katzensteiner, P. Reiter, C. Stummer, and M. Denk. Competence-driven project portfolio selection, scheduling and staff assignment. Central European Journal of Operations Research, 16(3):281-306, 2008.

[20] W. J. Gutjahr, S. Katzensteiner, P. Reiter, C. Stummer, and M. Denk. Multiobjective decision analysis for competence-oriented project portfolio selection. Technical report, Universität Wien, 2008.

[21] C. Heimerl and R. Kolisch. Scheduling and staffing multiple projects with a multi-skilled workforce. Technical report, Technische Universität München, 2007.

[22] M. H. A. Hendriks, B. Voeten, and L. H. Kroep. Human resource allocation in a multi-project R\&D environment: Resource capacity allocation and project portfolio planning in practice. International Journal of Project Management, 17(3):181-188, June 1999.

[23] G. Karthikeyan and K. Krishnaswamy. Assembly manpower allocation under proportionality constraints. European Journal of Operational Research, 44(1): 39-46, Jan. 1990.

[24] D. Krüger and A. Scholl. Managing and modelling general resource transfers in (multi-)project scheduling. Technical report, Universität Jena, 2008.

[25] W. Kwak, Y. Shi, and K. Jung. Human resource allocation in a CPA firm: A fuzzy set approach. Review of Quantitative Finance \& Accounting, 20(3): 277-290, May 2003. 
[26] D. A. Nembhard. Heuristic approach for assigning workers to tasks based on individual learning rates. International Journal of Production Research, 39(9): 1955-1968, 2001.

[27] D. A. Nembhard and N. Osothsilp. Learning and forgetting-based worker selection for tasks of varying complexity. Journal of the Operational Research Society, 56(5):576-587, 2005.

[28] D. A. Nembhard and M. V. Uzumeri. Individual-based description of learning within an organization. IEEE Transactions on Engineering Management, 47 (3):370-378, 2000.

[29] D. A. Nembhard and M. V. Uzumeri. Experiential learning and forgetting for manual and cognitive tasks. International Journal of Industrial Ergonomics, $25(4): 315-326,2000$.

[30] P. C. Pendharkar and G. H. Subramanian. An empirical study of icase learning curves and probability bounds for software development effort. European Journal of Operational Research, 183(3):1086-1096, Dec. 2007.

[31] S. Sayin and S. Karabati. Assigning cross-trained workers to departments: A two-stage optimization model to maximize utility and skill improvement. European Journal of Operational Research, 176(3):1643-1658, Feb. 2007.

[32] G. A. Süer and R. R. Tummaluri. Multi-period operator assignment considering skills, learning and forgetting in labour-intensive cells. International Journal of Production Research, 46(2):469-493, Jan. 2008.

[33] B. W. Taylor III, L. J. Moore, and E. R. Clayton. R\&D project selection and manpower allocation with integer nonlinear goal programming. Management Science, 28(10):1149-1158, Oct. 1982.

[34] G. L. Vairaktarakis. The value of resource flexibility in the resource-constrained job assignment problem. Management Science, 49(6):718-732, June 2003.

[35] V. Valls, A. Pérez, and S. Quintanilla. A graph colouring model for assigning a heterogeneous workforce to a given schedule. European Journal of Operational Research, 90(2):285-302, 1996.

[36] H. R. Varian. Intermediate Microeconomics: A Modern Approach. Norton, New York, 7th edition, 2006.

[37] A. Wächter and L. T. Biegler. On the implementation of a primal-dual interior point filter line search algorithm for large-scale nonlinear programming. Mathematical Programming, 106(1):25-57, 2006.

[38] T. Wright. Factors affecting the cost of airplanes. Journal of Aeronautical Science, 3:122-128, 1936. 
[39] M.-C. Wu and S.-H. Sun. A project scheduling and staff assignment model considering learning effect. The International Journal of Advanced Manufacturing Technology, 28(11-12):1190-1195, May 2006.

[40] Y.-K. Wu. On the manpower allocation within matrix organization: A fuzzy linear programming approach. European Journal of Operational Research, 183 (1):384-393, Nov. 2007.

[41] L. E. Yelle. The learning curve: Historical review and comprehensive survey. Decision Sciences, 10:302-328, 1979.

[42] M. Yoshimura, Y. Fujimi, K. Izui, and S. Nishiwaki. Decision-making support system for human resource allocation in product development projects. International Journal of Production Research, 44(5):831-848, Mar. 2006.

[43] P. H. Zipkin. Foundations of Inventory Management. McGraw-Hill, Boston, 2000 . 